\title{
Moorish architectural syntax and the reference to nature: a case study of Algiers
}

\author{
L. Chebaiki-Adli \& N. Chabbi-Chemrouk \\ Laboratoire architecture et environnement $L A E$, \\ Ecole polytechnique d'architecture et d'urbanisme, Algeria
}

\begin{abstract}
The analogy to nature in architectural conception refers to anatomy and logical structures, and helps to ease and facilitate knowledge related to buildings. Indeed, several centuries ago, since Eugène Violet-le-Duc and its relationship to the botanic, to Phillip Steadman and its biological analogy, many studies have already facilitated the understanding and apprehension of many complex systems, about buildings in the world. Besides these morphological and structural aspects, environmental preoccupations are now imposing themselves as new norms and values and reintroducing the quest for traditional and vernacular know-how as an alternative to liveable and sustainable settlements.

In Algiers, the exploration of traditional buildings, and Moorish architecture, which date from the $16^{\text {th }}$ century, interested many researchers who tried to elucidate their social and spatial laws of coherence. An excellent equilibrium was in effect, set up, by a subtle union between local culture and environmental adaptability.

It is in continuation of André Ravéreau's architectonics' studies that this paper will make an analytical study of a specific landscape, that of a 'Fahs', a traditional palatine residence situated at the extra-mural of the medieval historical town. This 'Fahs' constitutes an excellent example of equilibrated composition between architecture and nature. The objective of this study being the identification of the subtle conjugation between space syntax and many elements of nature, such as air, water and green spaces/gardens.
\end{abstract}

Keywords: Moorish architecture, space syntax, nature, horticulture phenomenon, green spaces and gardens, sky and solar, air, water. 


\section{Introduction: two ways of thought}

The relationship between architecture and nature doesn't constitute a new problematic. It has always appeared among the first privileges of the work of architectural design, since the 'historiographical', Classic and Gothic chains, until the new preoccupations of integration of natural factors in the human establishments, as tools of amelioration and optimisation of qualities of environments. Hence, we recover from these two ways of thought, the first way relative to morphological and constructive aspects, and the second one approaching the use and comfort criteria of the same subject.

The first way sends us back to interpretative models, stemming also from nature, where fundamental and typological architecture send back to natural existing models, creating by this, a parallelism between natural laws and design ones. So, nature has managed to influence the designer by its own laws, sometimes through the biological cycle, and sometimes through the harmonious structures.

It is on this basis, that of the science of nature, and its capacity to explain the history of architecture, that Eugene Violet-le-Duc [1] has developed his theories of transition of historical and architectural phases, in the middle age. Indeed, this was achieved by searching into biological and organic models. This theory is based on some stable signs, into a stylistic peak, without break, compared to human life cycle, and its evolution. This idea sends back to biorhythm, which would begin by birth and ends by death.

In addition, for Eugene Violet-le-Duc, the unity and the harmony created in a construction obey natural models, by its organics' unities. These models generate a logical deduction of the totality, as well as the fragments and the parts; and where the parts are as complete as the whole. These theories allowed afterward, another definition about architectural styles. It is that of the flora and fauna. Violet-le-Duc says, that we arrive to a logical process, and to form a set of laws, just like the natural bodies.

His link to the nature and the botanic lets appear a constructive logic, which raises less than a technical determinism than a natural order. After that, his organic consideration extends over the whole architectural reflexion, where he considers that the constructive logic is fundamentally based on anatomical order.

The second way looks back to the last decade where Philip Steadman [2] recapitulates the modes of thinking and the analogies to nature, through the history of architecture. He deduces some biological methods of design, based on the consideration of the nature as a prodigious inventor of several systems of engineering, saying that structural engineers look to forms in nature.

So, the concept of analogy in Steadman's studying sends up to the consideration that morphology - considered as a design science - might profitably continue to draw on biological thinking. He worked, this last ten years, on a new approach, based on the enumeration of morphological possibility in architectural arrangement, at a high level of abstraction, and with relationships to botanic. In spite that this approach isn't able to represent all types of buildings, it does however capture some of the constraints acting on a large class of built forms, 
imposed by geometrical necessity, and with some of 'generic functions' of architecture, such as the provision of natural light and the natural ventilation.

However, the fundamental questions of design led him to a scientific study, through its theory of 'architectural morphose'. This approach is based on the frame of all the topics of the building, and on the integration of the features of building design, as architectural one. These features are defined by topological relations of rooms to one another, by the structure of circulation route, and so on. At last, he found that certain historical building types, cluster in discrete zones within the space; while in other cases, it is possible to follow the movements of building types across the space, as their forms are changed in response to social and economic pressures, or to exploit new opportunities in building technology.

More recently, new attention has been directed towards both the useful and the functional qualities, especially in connection with energy and environmental questions. Therefore, the attention accorded to the comfort criteria and to the environmental quality, has led, among others, to vernacular architecture. The interest of these quests is to reveal its knowledge and know-how, which beneficiates from internal comfort, without recourse to active energies. This interest ensues from architectural criteria as well as space syntax, which in some cases conjugates with nature. This conjugation consists on one side on the exploitation of the climatic parameters, in the improvement and the optimization of the internal comfort of the buildings; and on the other side, it multiplies the link and the spatial interrelation with the nature -as a space- in its syntax. In this connection, we are particularly interested, by the Moorish architecture of Algiers, through the old palace, situated in the gone gardens of the Dey of Algiers, since the Ottoman age.

\section{The Moorish architecture of Algiers, the palace of the gardens of the Dey}

Built between 1791 and 1799, the palace of the gardens of the Dey, called 'Djenane Baba Hassen', is a representative building. Its typology follows that of palaces of the old Algiers the 'Fahs'. This last (the 'Fahs'), contained many gardens in the extra-mural of the old medieval city, that the actual 'Casbah'. It was an ideal place of relaxation and rest, where was located many houses and palaces, listed by many investigations, such as Klein [3], Golvin [4] and Marçais [5].

The palace of the old gardens of the Dey is characterised by its gardens, which surrounded it, and dominated the local landscape. Its extent exceeded eighteen hectares. Its importance is again appreciated through the space syntax of the palace, which enjoys a subtle conjugation between views- forms- comfort.

Having developed a profound study, based on stylistic and morphological studies, Cotereau [7] and Ravéreau [6] were able to assert the stylistic and functional particularity of this architecture. According to the rational type, and corresponding to the social needs. Therefore, on the occasion of the celebration of the centenary of the colonisation (in 1930), Cotereau [7] compares the architecture 


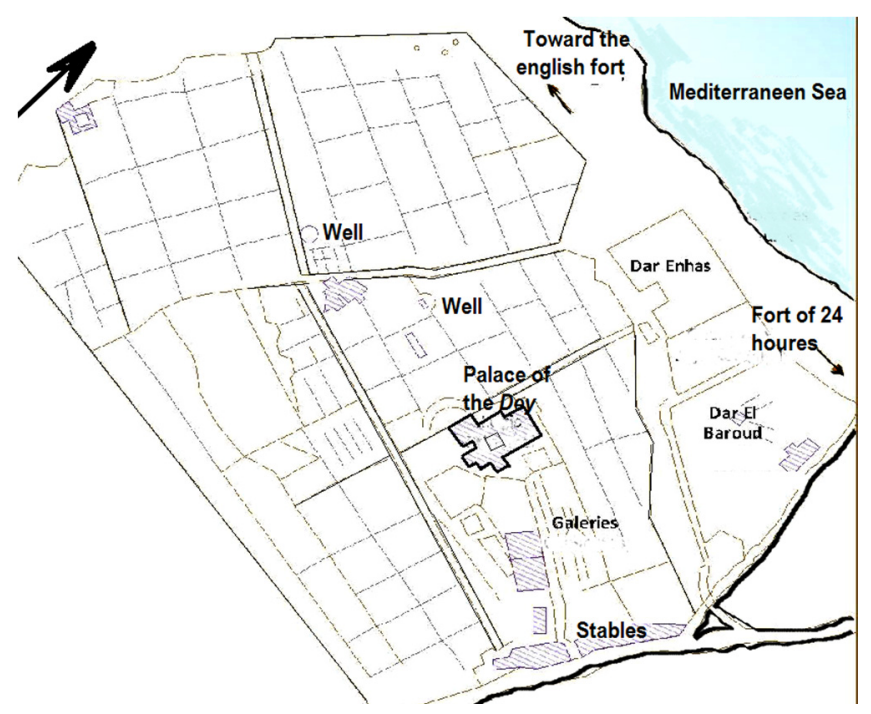

Figure 1: $\quad$ Site plan of the palace of the Dey's Gardens. (Source: [13, p. 219].)

of both houses and palaces of the old Algiers' Fahs, to the horticulture phenomenon; where the form of the medina houses spread in the gardens' environment to become a palace. This biological comparison qualifies this architecture as being a poly-cellular body, which, by maintaining the same main spaces of the intra-mural houses, some additional spaces multiply and develop on their extremity, in the Fahs.

On environmental preoccupations, vernacular know-how, and conservation of patrimonial heritage, several studies were carried out on this subject, in order to elucidate their solutions and modality of combination between spaces, architecture, comfort and regarding the economy of the energy.

Consequently, the palace of the ancient garden of the Dey presents a double interest; on one hand, by the conjugation of many elements of nature, such as the sky, the views, the water and the air; and on the other hand, by its important criteria of passivity and its capacity to improve comfort in its internal spaces.

\section{Harmony between nature and the space syntax of the palace}

Among the elements and characteristics employed in the architecture of the palace of the Dey, we are going to approach those more representative, tangible and significant aspects related to the subject of this paper. We will develop at first, the relation of the palace with green spaces and gardens, then with sky and sun, with water, and at last with air. 


\subsection{Green spaces and gardens}

Having a built-print more than two thousand meters scared, the palace contains cubic volumes in its extremities. These last are called ' $K$ 'bou'. They shelter spaces topped with domes, built by earth bricks. These ' $K$ 'bou' beneficiate from a strong relationship between the interior of the palace and its exterior; according to two directions, the first direction according to the three exterior façade of the $K^{\prime} b o u$ [8], and their views to the gardens and to the sea; then, the second direction that across the room, towards the internal 'patio', which constitutes the principal element of the palace. These $K^{\prime}$ 'bou are present at the fourth façades of the palace, in order to amplify the succession of the fresh air of the gardens during the hot season. So, there windows have relatively low dimension, comparing to the others, and are near the ground.

The garden, known by its fruit trees, its palm trees, its cedars, cypress, eucalyptus and bamboo, as well as its wells, fountains and aqueducts, shows its importance and its strong relation with the palace. This relation is more marked by the presence of more fruit trees (kitchen garden) in the south side and southeast side of the palace, according to the residential and intimate part of this latter. These trees reflect the interest given to the real life of the palace and to some characteristics included in its design, such as the visual and olfactive sensations, the privacy and the way of life. Whereas, the other trees (orchards), are located in the north and the northwest of the garden, in order to decrease the strength of winds. The breeze marinates, finer and higher, allow the visual continuity as well as the protection against the north winds.

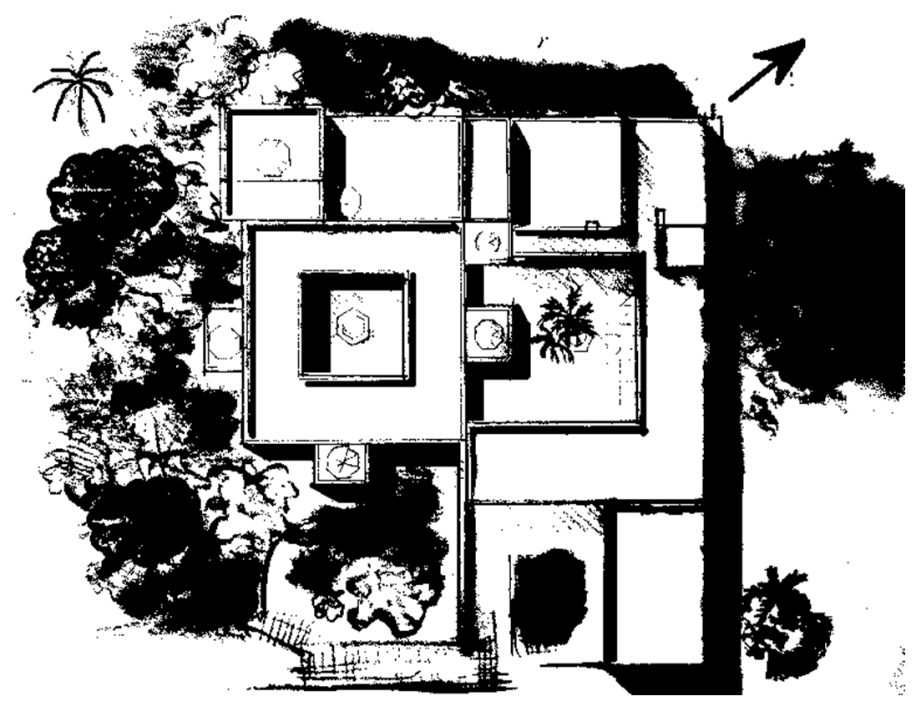

Figure 2: General plan of the palace of the Dey. (Source: sketch done by the author.) 
In both the patio and the courtyard, the presence of decorative plants, such as jasmine, basilica and other aromatic plants, spread by their perfumes and aromatic value, and used by the daily activities, shows the use of the nature in everyday life; this, besides the role which they bring in the refreshment of the patio and bordering rooms, which we shall study later on.

\subsection{Sky and sun}

The relation between sky and sun in the case study of the palace of the Dey is multiple. Being situated in the Mediterranean coast, where heat and sun are relatively soft, the space syntax of the palace is based on the two last rudimentary elements, that of the patio and the courtyard.

The composition and the distribution of spaces in the palace depend on these elements, and according to way of life and style life, besides the accessible terraces, strewed with domes, and playing the role of a fifth facade. This role is made by both the form of this last, and the functions of domes in ventilation and refreshment of the interior. So, the morphology of terraces, in tier and accessible, according to the soft incline of the ground, benefited from pleasant atmospheres, from surrounding sights, from the sky and the sun, principally accorded to the intimate part of the palace.

However, some ingenious elements are conjugated in order to reduce the strong sunbeams during the hot season. Galleries and arcs play the role of an intermediate and intercalary space, between opened and closed space, and between activity area and rest area.

The fourth galleries of arcs, having a depth exceeding two meters fifty, which turns superior to the depth of galleries in urban houses, constitute an excellent solution in solar protection. This protection is made by reducing direct sun radiation on the rooms, and by creating shade on vertical walls of rooms. This solution allows also taking natural aeration without excessive heating. For that purpose, several proportions go in consideration into this, such as the depth of galleries, the height of the gallery walls, surmounting the arcs, which is almost equal to one meter; the width of the patio which is eight meters, and at last the height of the patio, that constitute a double level. So, these parameters return in complementally harmony, in order to participate to the thermal comfort of the rooms, besides the natural circuit of aeration of these latter.

In summer, when the sun rays become the maximum, and when the height of the sun is almost sixty degree, in the middle of the day, the obstacles of sunshine multiply. Beside the sloping relief and the vegetation of gardens, the galleries offer at first a horizontal obstacle, through the floor, then a vertical obstacle through the walls surmounting the arcs. In addition, the walls' covered by ceramics, in the internal and external faces, play another thermal role, as an insulator.

However, the forms, sizes and measures of their windows, bring a complement to the previous aspect. In the outside facade, windows are reduced in their number, except those of the K'bou. Their windows, with squared form, are low and opened to the gardens. On the contrary, in the inside facades, besides the same type of windows, some wooden sculptured flaps, insure their closure, as well as the doors, letting appear small existing niches of aeration, above every opening. 


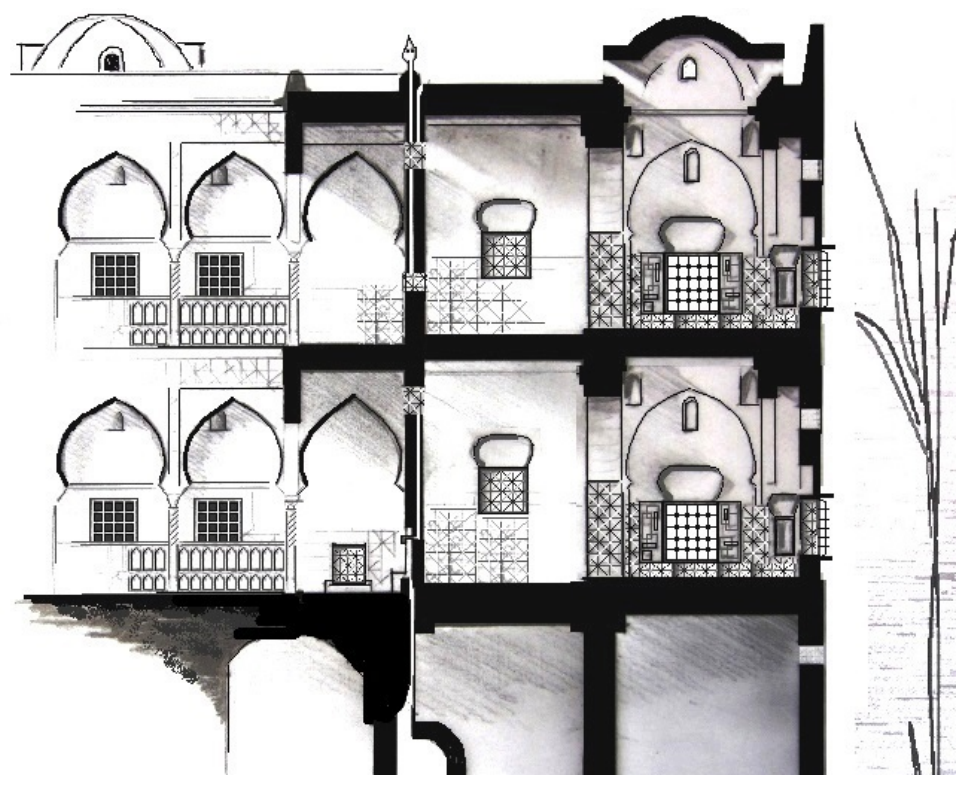

Figure 3: Section of the residence part of the palace of the Dey. (Source: sketch done by the author.)

Thus, many studies about the interior comfort of the Casbah' houses, by measuring and comparing the interior temperature to the exterior, demonstrate that during the hot days of the year, this typology allows a temperature reduction, about five degrees $\left(5^{\circ} \mathrm{C}\right)$, in the patio. While in winter, and according to its exposure, the patio temperature can increase about two degrees $\left(2^{\circ} \mathrm{C}\right)$ [9], comparing to the exterior temperature. So, in the green environment, where were the Algiers' Fahs, this aspect is again strengthen by the green spaces and gardens surrounding the palace, in addition to the fountains present in both the patio and the courtyard, which subsequently to the water evaporation, allow as well the refreshment of the air as its circulation.

\subsection{With air}

The aeration and the ventilation in the case study of the palace of the Dey are double. They obey to vertical and transversal logics.

Based on the principle that the hot air will rise in order to be automatically evacuated, the rooms of the palace are based on the same principle that all windows of principal rooms are of moderate size, and raised by thirty-five centimetres of the ground. These last absorb the fresh air, while the hot air is evacuated by the small and high niches, located in the walls and in the fourth pieces of the domes, overcoming every K'bou.

Besides the quoted elements, the rooms' ventilation increases by the chimney' effect. This latter is also concretised by another way, upward the patio, in order to 
clear heat and smell of the building. Whereas, the transversal ventilation, it achieved by the opposite opening, whether it is in the internal facade or in the outside facade of the palace.

In addition to these elements, other small niches are situated in the internal facade of the palace. They serve to put light in the night, to both rooms and galleries. They serve also to evacuate smokes of the oil lamp, used during the ottoman period, through conduct embedded in the wall, in potteries of terra-cotta, and resulting into the small wall of the terraces.

These same conducts ensure another role, as additional ventilation, during the day. The air which gets there, will cool during its route (in the conduct), and will consequently refresh the room, by penetrating it, and then by moving the hot air toward the small and high opening.

So, we deduce that these elements are conjugated with subtlety, in order to bring a maximum of comfort to the internal spaces; in add to their important and manifested semantic level, which bring a particular stylistic character.



Figure 4: Plan of the second floor (patio) of the palace of the Dey. (Source: [4, p. 94].) 


\subsection{Recycling water}

The water supply in Arabo-Muslim architecture rested strongly on collective installation. Every house possessed its own system of collection, distribution and recycling of rain water; then of a collective system of evacuation.

Having its own system of recycling of rain water, the palace had also wells. Its architecture is based on the principle of collection then reserve the rain water. It is by the soft incline of terraces' floor, covered by terra-cotta tiles also, that rain water are brought towards conducts unscripted in the interior rooms' walls. These latter are constituted by the same potteries elements quoted previously, but ordered according to the sense of fluids, that is in descent. This water will be led toward a build reserve in the underground called 'jeb', reserved for clean water, which disappeared today. Toward this wall' conduct also, a wall' fountain exists, benefiting from the rain water, and offering clean water toward a decorative ceramic wall' fountain. In spite of this, the 'jeb' being near the patio' floor included another mode of recuperation of the rain water, through closer conduct.

During the hot months of the year, reserved water can be used directly in the underground, by access in the edges of the tank, or through the well situated according to the vertical axis, of wet rooms of the palace. Being stacked, the kitchen situated in the second floor and benefiting from an oven, serves as a source of heat for the hammam (Moorish bath) situated just above.

All these elements complete itself, in an interpenetrating harmony, with stylistic criteria, in order to bring a maximum of comfort and refreshment during the hot days of the year, according to no consumption energies and without harmful impact on the nature.

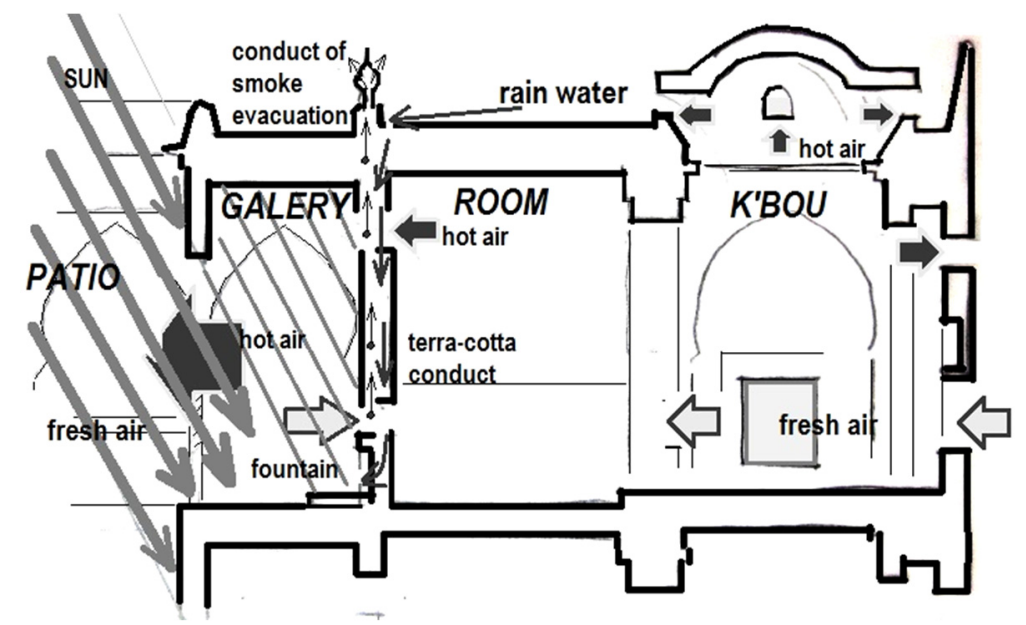

Figure 5: Some processes of ventilation and recycling water of the palace of the Dey. (Source: sketch done by the author.) 


\subsection{Plants and vegetal decoration}

Among many processes of decoration in the palace of the Dey, the wring of the stone' columns of the patio, reminding trunks' palm trees, doesn't constitute the only existing aspect, because all the walls' ceramics are based on the composition of tile brilliant ceramics, with geometric, floral and epigraphic designs. The varied colours and plants' decoration dominate on these ones, which do always offer a repetitive rhythm on a diagonal background, in order to allow harmony and unity on decorating surfaces. Between the employed plants, we cote the rose window, the grapes and the acanthi leaf.

In spite that these ceramic file' origin is varied; (from Tunisia, Italia and Spain) they offer a harmonious conjugation between Moorish style and nature.

\section{Conclusion: some processes to harmonise architecture and nature}

The reference of architecture to nature is more and more studied. Besides the stylistic cycle introduced by Eugene Violet-le-Duc, then his analogy to the anatomy and to the botany, until the environmental process of human establishments evoked by Steadman, we support the both forms of thought, through the Moorish architecture, of the old Algiers from the middle age, and especially through the old palace of the gardens of the Dey.

The interest and the particularity which presents the space syntax of the palace are double. From one hand, its architectural composition, compared to the horticulture phenomenon, authorizes the reuse of its syntactical criteria, and its adaptation into another context or in new requirements.

On the other hand, its syntax based on passivity and constructive ingenuity, involves many solutions to optimise the interior comfort, through different processes, such as the rooms' ventilation, the relations of spaces with surrounding gardens and plants, the introversion by both of patio and courtyard, described as the heart of an alive organism, and at last, the processes in supplying and recycling water. All these elements contribute to the liveliness of the palace, to the continuation of its life cycle, and to its consideration as a living body.



Figure 6: Some models of ceramic tiles of the palace of the Dey. (Source: photos taken by the author.) 


\section{References}

[1] Recht, R., Viollet-le-Duc et Gottfried Sempe leurs conceptions $d u$ patrimoine monumental, pp. 155-168. Revue germanique internationale [En ligne], 13 | 2000, mis en ligne le 31 août 2011, consulté le 12 octobre 2012. URL: http://rgi.revues.org/780

[2] Steadman, P., The evolution of designs biological analogy in architecture and the applied arts, Routledge Taylor and Francis Group, 2008.

[3] Klein, H., Feuillets d'El Djezair, Imprimerie orientale Fontana Frère \& Cie, Alger, 1910.

[4] Golvin, L., Palais et demeures d'Alger à la période ottoman, Edisud, 1988.

[5] Marçais, G., Manuel d'art musulman l'architecture Tunisie, Algérie, Maroc, Espagne, Sicile, tome II ; édition Auguste Picard Paris 1927.

[6] Ravéreau, A., La casbah d'Alger et le site créa la ville, collection Sinbad, Actes Sud, 1989.

[7] Cotereau, J., La maison mauresque, chantier Nord Africain, 1931.

[8] Missoum, S., Alger à l'époque Ottomane la médina et la maison traditionnelle; INAS, Alger, 2003.

[9] Merrad, D., Evaluation de la qualité environnementale dans le secteur sauvegardé cas d'étude Casbah d'Alger, Mémoire de Magister Laboratoire Architecture et Environnement, pp. 139-141, 2012.

[10] Deluz, J.J., L'urbanisme et l'architecture d'Alger Aperçu critique, Liege, Mardaga, 1988.

[11] Deluz, J.J., Le tout et le fragment, Barzakh éditions, Alger, 2010

[12] Bourouiba, R., Apport de l'Algérie à l'architecture religieuse araboislamique, office des publications universitaires, Alger, 1986.

[13] Saidouni, N., la vie rurale dans l'algérois 1791-1830, Université de Provence, 1988.

[14] Lézine, A., architecture de l'Ifriqiya recherches sur les monuments aghlabides, librairie C. Klincksieck, France, 1966.

[15] Ricard, P., pour comprendre l'art musulman dans l'Afrique du nord et en Espagne, édition Hachette, 1924. 